\title{
The Research of Existing Problems and Countermeasures in College TaiChi Chuan Teaching
}

\author{
Hong YANG \& Xingwei GUO \\ Changchun Guanghua school, Changchun, China
}

\begin{abstract}
Taijiquan has now become the majority of colleges and universities teaching in physical education a compulsory subject in the project, one of the younger students the characteristics of active and need to loose body pause, slow movements of tai chi form of contrast. Means and methods of teaching as a result of the lag, making the students interested in learning tai chi to reduce, the reason for an elective just to complete their education requirements necessary credits. The main purpose of this study is to assemble logically the variety of present teaching methods, and then do teaching trial, and last to select the optimum combination. And provide a basis for the improvement of Taijiquan teaching methods of University.

KEYWORD: TaiChi Chuan teaching; Teaching methods; Problem; Countermeasures
\end{abstract}

\section{INTRODUCTION}

Taijiquan is one of valuable sports cultural heritage in our country, now has a wide range of popular, practicing the crowd more 24 style Taijiquan is the evolution of the traditional Taijiquan and streamline routines. Taijiquan movements of a complete set of sofe, coherent round live, back and forth, back and forth continuously, long-term practicing Taijiquan can have physical and mental pleasure, cultivate one's morality raises a gender, to prevent and cure diseases and prolong life, and so on. In addition, as a result of the Taijiquan movement intensity is moderate, suitable for different age groups of fitness crowd involved, and the advantage of sports venues, equipment requirements, in the sports teaching in colleges and universities has been widely carried out, especially the 24 type simplified tai chi chuan. But we found in the Taijiquan repertoire teaching, due to the complexity of Taijiquan movements is various, changeful running route, theoretic esoteric etc, affect the interest of a beginner to learn tai chi chuan, cause they feel boring, difficult to quickly grasp the Taijiquan movement effectively. Such reasons, explore new teaching methods, and promote the Taijiquan teaching effect is worth every martial arts teaching teachers in colleges and universities must focus on the problem.

\section{THE PROBLEMS OF TAICHI CHUAN TEACHING IN COLLEGE}

Wushu practice unlike regular physical education teaching contents, but tai chi routines more has its own particularity, with the popularity of Taijiquan in the universities sports teaching, tai chi also gradually diverse teaching methods and means. However, previous study of Taijiquan teaching methods are mostly limited to theoretical level, experimental validation study is less, and the research methods are mostly limited to a single teaching method research or its comparison with conventional teaching methods. Should be said that all kinds of teaching methods and different, each have their own unique, therefore, it is necessary to try to optimize the combination of different teaching methods for effective to promote the Taijiquan teaching in colleges and universities.

Conventional Taijiquan teaching is through stepby-step teaching steps, emphasize every action, every type of organization students teaching action details. And Taijiquan techniques of a complete set of lines change complex, beginners when too much emphasis on the details of the action, the students often chaotic due to the action sequence, attend, affect the efficiency of practice, does not favor the Taijiquan teaching smoothly.

\section{TAIJIQUAN TEACHING COUNTERMEASURES}

Framework of this study is the teaching, the combination of good practice, and support groups for tai chi exercises teaching, optimizing teaching composition is Taijiquan teaching method innovation and rich in colleges and universities, the application of it may accelerate the process of Taijiquan teaching, 
improving college students' interest in learning tai chi chuan. At the same time, the other teachers or scholars engaged in research on teaching sports technology subject sprang out. Therefore, the innovation points of this study is to present in the sports teaching several teaching methods of the core part of a mature, reasonable optimization combination, and applied it in the teaching of the university of twenty-four Taijiquan repertoire.

\subsection{The study object}

The object of study for Changchun Guanghua College class of 2012 college students, random selection of same level four class nature. Of four natural class USES the combination of different teaching for one academic year of Taijiquan teaching, the teaching test performed by the same teacher.

\subsection{The research methods}

\subsubsection{Documentation}

By CNKI database retrieval framework and situational teaching knowledge, at the same time to retrieve the relevant literature in the sports teaching. Consult literature material, found that frame teaching or similar to the framework of teaching essence of teaching method in the sports teaching the application of the research was less than 5 references; Nearly a decade in the sports teaching the application of situational teaching research with 20 references, and most in primary and secondary schools as the research object. How to add background music or to Taijiquan teaching establishment situation such as Taijiquan image technology to promote teaching.

\subsubsection{The orthogonal experiment design}

Different combination of teaching according to the orthogonal design test method to determine. L4 (23) orthogonal experimental design method, and the arrangement of the teaching experiment, on the basis of access to information, identify the main factors influencing the effect of wushu teaching and level.

A factor (teaching methods): level 1 is the common teaching (see teachers will one sectional interpretation and slow exercise movement to learn A teacher get $A$ teacher practice action name and password password action name to practice). Level 2 framework for teaching a section (see teachers will explain each type action is a framework structure of "fist slow fast teaching" the teacher get a teacher practice action framework name and password password action framework name practice.)

Includes the $\mathrm{B}$ factor (practice): practice for collective, review the content level 1 for personal practice, the teachers' guidance. Level 2 practice for group, the teacher guide, $6-8$ people per team.

$\mathrm{C}$ (teaching media): level 1 is watching the multimedia learning after complete routine exercise; in the practice the process of auxiliary multimedia and no action password background music into practice; Finally, the multimedia will complete comparative study. Level 2 is watching the multimedia learning after complete routine exercise; in the practice the process of auxiliary multimedia and have action password background music into practice; Finally, the multimedia will complete comparative study.

\subsubsection{Measurement}

Before teaching respectively to test the students of class four several physical quality indexes, such as balance (time) left foot by one foot stand, in situ vertical jump, push-ups and sit-ups and other indicators. In the completion of a school year teaching, according to the Taijiquan teaching assessment, please Taijiquan experienced teacher class for all trials conducted double-blind evaluation.

\subsubsection{Questionnaire investigation}

By means of open questionnaire before and after the teaching practice tai chi to all the students in experimental class of acquisition of frequency in the investigation.

\subsubsection{Mathematical statistics}

In EXCEL for all data statistics, and then using SPSS11.5 software for data of the differences between different groups with single factor analysis of variance to test of significance $(\mathrm{P}<0.05$ for significant standard).

\subsection{Analysis and discussion}

\subsubsection{Framework teaching effective use}

Informally, teaching framework is teaching in the teaching process to make the students know the general structure of the teaching content and master of teaching content in detail later in requirements. Which follow the "overall level one whole" ideological line. It is well known that tai chi chuan technology of a complete set of movements is various, route complex, deep, theoretic impression for beginners is difficult to grasp, and then shrink learning interest greatly. Framework of teaching used in Taijiquan teaching refers to let the students master every movement (especially difficult action) of general architecture, will be complex and everywhere is the Taijiquan movement arc movement and speed slow, into a rapid analysis of the long reach of teaching, the so-called "slow boxing teaching a fast. Because of this phase is the start of the beginners to learn a new skill, known as the generalization stage, at this point in the cerebral cortex inhibition has not been established, excitement and inhibition process according to the motion law of the cerebral cortex itself and spread, the conditional reflex temporary connection is not stable, this stage should pay 
attention to the focus, the key is to simplify the twenty-four Taijiquan movement of the frame structure of each type of" slow boxing quick teaching ", emphasize the main steps of action, unfavorable and overmuch technical details required action. Tai chi skills at this stage the emphasis is on the main is a behavioral essentials and basic action route. When the students for the whole routines that the path of mastery, and then to nature, in strict accordance with the characteristics of Taijiquan teaching.

This stage the main task is to change the front in the process of teaching in mastering long fist style, formed by the action of combined with breathing, the mind, after repeated practice, gradual transition, and form strong, correct action specifications, strengthen students' understanding of Taijiquan style. Besides emphasize action details, but also pay attention to the "chang chuan training methods" from the previous shift to "slow practice", namely from the beginning to the end according to tai chi arc movement and slow to practice, to further consolidate the students on the degree of master Taijiquan techniques. And at this stage is the consolidation and automation phase of the motor skill learning phase, the autonomic nervous activity and body coordination of athletic neural activity has become a part of the motor skills. At this point should be emphasized to practice regularly and refinement, and to strengthen the understanding of movement inherent law and learning. In fact, the "slow boxing quick teach" exactly reflect the core of the framework of teaching, both have the same place.

Framework at various stages of teaching techniques is to grasp the learning characteristics, to simplify the overall structure of the action to practice, this stage is just corresponding movement skill learning in the physical characteristics of generalization and differentiation stage, differentiation and inhibition of the brain is not fixed, only suitable for thick line of learning, but not too much emphasis on the details of the action. And when the action broad-brush skilled action again after the details of the requirements and reading practice, the corresponding action skill learning automation stage of physical characteristics, differentiation and inhibition of the brain is relatively fixed, can be based on the analysis of the techniques for higher, stricter and more fine improvement.

\subsubsection{Rainfall distribution on group the positive role of practice}

After the collective teaching, carries on the personal practice or 6-8 for a team to team to practice. In the process of group exercise, team members can discuss and communicate with each other between each other to correct and improve. Such exercises can make students play their respective advantages, both complement each other, under the interaction of tips and supervise and urge, to form a positive learning atmosphere. This on the one hand, with the special educational circles now popular "microteaching" has a similar place. The microteaching is equipped with special classroom television camera, video systems, with the help of the cameras and video recorders, communication equipment, skills training and teaching system of teaching research. It has been translated as "micro teaching". The teaching process generally includes three steps: the lounge, self evaluation analysis and discussion. "Microteaching" was at Stanford University in 1963 to cultivate middle school teachers of the course, as basic teaching skill training. In some university in Europe and the United States, Japan, almost as a kind of education and training of education practice before. It is a composed of a few students classroom, guided by the modern education theory, through the strength of the multiple feedback, disciplines, according to the strict training for students, so that its duty and work closely with.

The latest research results show that the function of music can accelerate the consolidation process of motor skill, improve technology, stimulate muscle activity, helps to improve the density of practice. The former Soviet union institute of education sciences ugo, khoza, Mr Rove's research, according to the report USES the function of music teaching form has a physiological aspects of basis. Because according to advantage rule, to relax the attention to enjoyable with stimulation, not only will not bring harm to the main activities, and on the contrary, reflection to strengthen and relieve this activity, can cause the antagonist muscles relax more fully and don't participate in activities. Choose appropriate practice Taijiquan exercise can adjust the music accompaniment of rhythm and speed, and prompt behavioral essentials, atmosphere rendering performance, through music, stimulate the auditory nerve trainees, raise people's feeling of beauty, for practitioners to create the good situation and artistic conception for practice, highlight the artistic quality of tai chi chuan the project itself.

Tai chi practice emphasizes the combination of movements, breathing and cognitive, otherwise the Taijiquan movement is flashy, ACTS have empty frame, cannot give full play to the fitness value of Taijiquan. In the process of beginners Taijiquan movements, we want to explain every recruit students, each type of attack and defense of Taijiquan techniques meaning and practical skills to let students learning needs a certain situation. We are through in the process of teaching auxiliary some specially selected for Taijiquan movement rhythm of the background music, and even special practice scenarios such as Yin and Yang gossip to practitioners build a special scene atmosphere, in order to better promote learning tai chi chuan, raise the level of practice. 


\subsubsection{The reasonable application of multimedia teaching and music background}

At the beginning of the new motor skills learning mainly is to strengthen the beginner's intuitive feeling, have an intuitive knowledge of sports skills and grasp, teachers should through the correct demonstration and the interpretation of image so that the students establish the correct concept of action. Students in the process of imitating practice, through feedback to build muscle activity of proprioception. And multimedia teaching just play at this stage the unmatched by other teaching methods. From a physiological standpoint, the function of the left brain and right brain is completely different. RogerW, Dr Sperry, through "split" brain research found that the left and right brain have different functions. The brain is mainly responsible for or tube image thinking, intuition and creativity is the control center of the arts and sports, music, art, exercise the brain, the left hemisphere is mainly engaged in logical thinking, is mainly rely on the language analysis, judgment and abstract generalization of center, is the language of brain. Left and right hemispheres of the brain function with complementary, the two sides and close cooperation. The latest research results show that the function of music can accelerate the consolidation process of motor skill, improve technology, stimulate muscle activity, helps to improve the density of practice. The former Soviet union institute of education sciences especially - doug khoza, $\mathrm{Mr}$ Rove's research, according to the report USES the function of the teaching form of music is a physiological aspects. Because according to advantage rule, to relax the attention to enjoyable with stimulation, not only will not bring harm to the main activities, and on the contrary, the reflection to strengthen and relieve this activity, can cause muscle and more fully relax muscles don't participate in activities. Choose appropriate practice Taijiquan exercise can adjust the music accompaniment of rhythm and speed, and prompt behavioral essentials, atmosphere rendering performance, through music, stimulate the auditory nerve trainees, raise people's feeling of beauty, for practitioners to create the good situation and artistic conception for practice, highlight the artistic quality of tai chi chuan the project itself.

\subsubsection{Effective combination of a variety of teaching methods}

It should be said that in the process of sports teaching a variety of colorful teaching method, the method used, the more to a certain extent led to the greater the difficulty, and the longer teaching is required. And through reasonable optimization selection and reasonable arrangement of teaching content, it can get twice the result with half the effort teaching effect. The four experimental class into 24 of the present study the best is the combination of experimental class four, grade and can learn from the calculation, because of various factors are $\mathrm{K} 2$ values greater than $\mathrm{K} 1$ values, remember to $\mathrm{A} 2+\mathrm{B} 2+\mathrm{C} 2$. That is combination of $\mathrm{A} 2+\mathrm{B} 2+\mathrm{C} 2$ teaching effect should be the best, but in L4 (23) orthogonal test design in $\mathrm{A} 2+\mathrm{B} 2+\mathrm{C} 2$ combination not contained within the design.

$\mathrm{A} 2+\mathrm{B} 2, \mathrm{C} 1$ and $\mathrm{A} 2+\mathrm{B} 2+\mathrm{C} 2$ which kind of test more effective combination, it remains to be further validated experiment teaching. The innovation of teaching methods is the key to solve the problem of current college students Taijiquan teaching, through the reasonable combination of teaching methods, making students learning interest to this project, active, not passive to learn to practice. So, at the same time of received good teaching effect, and fitness activities for college students to enter society after laid a solid foundation. Teaching method study is endless, this research is in the Taijiquan teaching in colleges and universities teachers have played an important role in a topic, with the deepening of the research, the Taijiquan teaching in colleges and universities will become more brilliant tomorrow.

\section{CONCLUSION}

The teaching results of this study was, teaching portfolio $\mathrm{A} 2+\mathrm{B} 2+\mathrm{C} 1$ best, and then in turn is $\mathrm{B} 1+$ $\mathrm{C} 2$ and $\mathrm{A} 1+\mathrm{A} 2+\mathrm{B} 2+\mathrm{C} 2, \mathrm{~A} 1, \mathrm{~B} 1$ and $\mathrm{C} 1$ worst teaching combination. As a result of the three teaching factors weight value is different, the best teaching portfolio should be $\mathrm{A} 2+\mathrm{B} 2+\mathrm{C} 2$ teaching portfolio.

Framework for teaching in the teaching of Taijiquan is the innovation of teaching methods of Taijiquan, the application can improve the efficiency of students' memory routines, promote the progress of the teaching process. Team training can give full play to group members of the team cooperation ability, give full play to each team members of their own advantages, complement each other, learn from each other, promote each other. At the same time, it can exercise the student using means such as thinking, language, form, strengthen the sports skill. Auxiliary multimedia and contains action password background music in Taijiquan teaching, can improve the students' interest in practice, thus effectively improving the teaching efficiency.

\section{REFERENCES}

[1] Tessier D, Sarrazin P, Ntoumanis N. The effect of an intervertion to improve newly qualified teachers' interpersonal style, students motivation and psychological need satisfaction in sport-based physical education. CONTEMPORARY EDUCATIONAL PSYCHOLOGY, 2010, (35):242-253. 